\title{
Adverse Drug Reaction Monitoring and Reporting at H.S.K Hospital and Research Center-Bagalkot
}

\author{
Venkaraddi Magannavar Chandrashekhar ${ }^{1}$, Allu Harikrishna ${ }^{2}$, Prasanna kumar $^{2}$, Nambari \\ Hemanthkumar', Majjaru Chandrakanth ${ }^{2}$
}

${ }^{1}$ Department of Clinical Pharmacy in H.S.K College of Pharmacy,Karnataka, INDIA.

${ }^{2}$ Pharm.D Students in H.S.K College of Pharmacy, Karnataka, INDIA.

\begin{abstract}
Introduction: Adverse drug reactions (ADRs) Reporting is provides safety and Improves strength of Drug adverse reaction to the Drug. Such ADR reporting programs encourage surveillance for ADRs, promote the reporting of ADRs and stimulate the education of health professionals regarding potential ADRs. Objective: ADR monitoring is an important part of post marketing surveillance which helps in generating data on safety of medications. Main Aim to ADRs Monitoring is to the Promoting rational use of drugs, Safe use of Medicine, Improving patient care, improving public health. Methods and Material: This was a prospective, observational, voluntary reporting study. Study was conducted in H.S.K Hospital and Research centre, Navanagar, Bagalkot, Karnataka. Samples was collected from Skinand VD, General Medicine, Pediatric Department and in all age groups. We are taken support of WHO Scale, Naranjo scale, Hartwig scale, CDSCO Form to collect the data. Result: In our study observed 77 ADRs in overall 59 patients of with ADRs reported from 180 patients was reported from both inpatients and outpatients, in this outpatients were less compared to inpatient. Highest ADRs are reported in $(28.4 \%)$ skin rashes, General Medicine $(69.7 \%)$ in different organs like Hematology, Cardiology, and Central nerves system, Hepatic, Renal, Endocrine, Respiratory and Gastrointestinal. In those study Antibiotic (20.8\%) were causes high ADRs in those moderate level (75.3\%) ADRs high than sever (10.4) in those as per WHO scale casual assessment probable (46.8\%) ADRs were high. As per age group Incidence of ADRs among $0-15$ age is $1.7 \%$ is less than $16-30$ age group is $32.2 \%$ and is significantly higher than other age groups. In these studies we got type-A reactions as $26.08 \%$ is less than type-B reactions as $73.92 \%$. Conclusion: The present evaluation has revealed opportunities for interventions especially for the avoidable ADRs which will help in promoting safer drug use, information to the healthcare professionals. Improve the quality of patient care and educate to increase awareness.
\end{abstract}

Key words: Adverse Drug reaction, Skin and VD, Antibiotics, Hemolytic anemia, Polypharmacy.

\section{INTRODUCTION}

Adverse drug reactions (ADRs) are considered as one among the leading causes of morbidity and mortality. Around $10 \%$ of hospital admissions are estimated to be due to ADRs and about $5-20 \%$ of hospitalised patients experience a serious ADR. ${ }^{1-3}$ Reporting of ADRs has become an important component of monitoring and evaluation activities performed in hospitals. ${ }^{4}$ Such ADR reporting programs encourage surveillance for ADRs, promote the reporting of $\mathrm{ADRs}$ and stimulate the education of health professionals regarding potential ADRs. ${ }^{5}$ A productive hospital-based reporting program can be instrumental in providing valuable information regarding potential problems of drug usage in an institution. Through these efforts, problems are identified and resolved, which results in continuous improvement in patient care. ${ }^{6}$ Spontaneous reporting program, a common method of drug surveillance is capable of recognizing ADRs in the daily medical practice, even though under reporting and absence of information on number of people actually exposed to the drug are its disadvantages. $^{7,8}$

Periodic evaluation of ADRs reported in a hospital helps in characterizing the pattern
Submitted date :06/01/2015 Accepted date :03/04/2016

DOI: 10.5530/ijopp.9.1.10

Address for correspondence: Dr. Allu Harikrishna,

Department of Clinical Pharmacy in H.S.KCollege of Pharmacy,

Karnataka, INDIA. Phno:+919494610789 E-mail:dr.hemanth.pharmd@ gmail.com

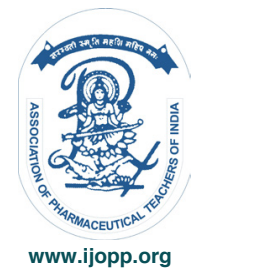


of ADRs and thereby help in designing steps to improve the safety of drug use in the daily routine set up. ${ }^{9}$ Data generated from a hospital set up further contributes to the national and international databases on ADRs which will ultimately contribute in drug safety decisions and may serve as a basis for product-labeling revision and design patient education strategies. ${ }^{10}$ Even though India started participating in the World Health Organization (WHO) pharmacovigilance program few years ago, monitoring and reporting of ADRs is still in its infancy in this developing country. ${ }^{11}$ Since, from November 2004, Central Drugs Standard Control Organization, Ministry of Health and Family Welfare, Government of India launched the National Pharmacovigilance Programme which is expected to be successful since this has been structured taking into consideration the past deficiencies of similar efforts. ${ }^{12}$ H.S.K Hospital is 820 -bedded tertiary care teaching hospital in North-Karnataka, India. Pharmacists in organized health care systems should develop comprehensive, ongoing programs for monitoring and reporting adverse drug reactions. ${ }^{13} \mathrm{It}$ is the pharmacist's responsibility and professional obligation to report any suspected ADRs. ADR-monitoring and reporting programs encourage ADR surveillance, facilitate ADR documentation, promote the reporting of ADRs, provide a mechanism for monitoring the safety of drug use in high-risk patient populations, and stimulate the education of health professionals regarding potential ADRs.

ASHP defines a significant ADR as any unexpected, unintended, undesired, or excessive response to a drug that, (i) Requires discontinuing the drug (therapeutic or diagnostic), (ii) Requires changing the drug therapy, (iii) Requires modifying the dose (except for minor dosage adjustments), (iv) Necessitates admission to a hospital, (v) Prolongs stay in a health care facility, (vi) Necessitates supportive treatment, (vii) Significantly complicates diagnosis, (viii) Negatively affects prognosis, or results in temporary or permanent harm, disability, or death. ${ }^{13}$

Several other definitions of ADRs exist, including those of the WHO, ${ }^{13}$ Karch and Lasagna,${ }^{14}$ and the Food and Drug Administration (FDA). ${ }^{15}$

WHO: ${ }^{13}$ "Any response to a drug which is noxious and unintended, and which occurs at doses normally used in man for prophylaxis, diagnosis, or therapy of disease, or for the modification of physiological function".

Karch and Lasagna: "Any response to a drug that is noxious and unintended, and that occurs at doses used in humans for prophylaxis, diagnosis, or therapy, excluding failure to accomplish the intended purpose."
FDA: ${ }^{15}$ For reporting purposes, FDA categorizes a serious adverse event (events relating to drugs or devices) as one in which "the patient outcome is death, lifethreatening (real risk of dying), hospitalization (initial or prolonged), disability (significant, persistent, or permanent), congenital anomaly, or required intervention to prevent permanent impairment or damage."

The perspective, it may be helpful to note events that are not classified as ADRs. A side effect is defined by ASHP as an expected, well-known reaction resulting in little or no change in patient management (e.g., drowsiness or dry mouth due to administration of certain antihistamines or nausea associated with the use of antineoplastics). An ongoing ADR-monitoring and reporting program can provide benefits to the organization, pharmacists, other health care professionals, and patients. These benefits include (but are not limited to) the following, (i) providing an indirect measure of the quality of pharmaceutical care through identification of preventable ADRs and anticipatory surveillance for high-risk drugs or patients. (ii) Complementing organizational risk-management activities and efforts to minimize liability. (iii) Assessing the safety of drug therapies, especially recently approved drugs. (iv) Measuring ADR incidence. (v) Educating health care professionals and patients about drug effects and increasing their level of awareness regarding ADRs. (vi) Providing quality-assurance screening findings for use in drug-use evaluation programs. (vii) Measuring the economic impact of ADR prevention as manifested through reduced hospitalization, optimal and economical drug use, and minimized organizational liability.

\section{Classification of Adverse drug reaction: ${ }^{16}$ Type-A} (Augmented): Commonest (up to 70\%)-Dose dependent, severity increases with dose. Preventable in most part by slow introduction of low dosages. Predictable by the pharmacological mechanisms, e.g., hypotension by beta-blockers, hypoglycemia caused by insulin or oral hypoglycemic, or NSAID induced gastric ulcers.

Type-B (Bizarre): Rare, idiosyncratic, genetically determined, unpredictable, mechanisms are unknown, Serious, can be fatal; unrelated to the dose, e.g., hepatitis caused by halothane, aplastic Anaemia caused by chloramphenicol, neuroleptic malignant syndrome caused by some anaesthetics and antipsychotics.

Type-C (Continuous drug use): Occurs as a result of continuous drug use. May be irreversible, unexpected, unpredictable, e.g., tardive dyskinesia by antipsychotics, 
dementia by anticholinergic medications.

Type-D (Delayed): Delayed occurrence of ADRs, even after the cessation of treatment, e.g., corneal opacities after thioridazine, ophthalmopathy after chloroquine, or pulmonary/peritoneal fibrosis by methyserzide.

Type-E (End of dose): Withdrawal reactions. Occurs typically with the depressant drugs, e.g., hypertension and restlessness in opiate abstainer, seizures on alcohol or benzodiazepines withdrawal; first dose hypotension caused by alpha-blockers (Prazosin) or ACE inhibitors.

Type-F (Failure of therapy): Results from the ineffective treatment (previously excluded from analysis according to WHO definition), e.g., accelerated hypertension because of inefficient control.

\section{METHODS AND METHODOLOGY}

Spontaneous reporting and intensive monitoring are the most suitable methods in a clinical/hospital set up.

This Study was design a prospective, observational, voluntary reporting study.

This Study was carried out in H.S.K Hospital and Research centre, Bagalkot. It is a tertiary are teaching hospital associated to S.N. Medical College. It is a 820 bedded general hospital run by the BVV Sangha. It is one of the premier institutes in Karnataka with around 12 specialties, serving to the health care needs of a huge population.

This Study was based only on those patients who experienced an adverse reaction to medicine use, either during their stay in hospital or outside the hospital and visited the outpatient departments of H.S.K hospital and ultimately reported to clinical pharmacist.

The study criteria was designed in following view.

\section{Inclusion criteria}

Patients, with ADR, of any age of either sex, has of reported to the clinical pharmacist from inpatient and outpatient setup of different department of H.S.K COP, Bagalkot.

\section{Exclusion criteria}

The ADR that due to

Medication errors, over prescribing, over dosing/excess consumption.

Indian Journal of Pharmacy Practice, Vol 9, Issue 1, Jan-Mar, 2016
Drug-Drug interaction, Drug-food interaction, Drug interaction with a use of alternative system of medicine.

\section{Age criteria}

The study considered the following age groups.

Patient of age less than 0-15 yrs or equal are considered as infants, children, adolescents.

Patient of age group 16-30 year are consider as young adult.

Patient of age $31-45$ years adults and

Patient of age 46-60 years older adults.

Patients of age 61-75 years elderly adults and very elderly adults above 75 years above are considered as geriatrics.

This study was carried out for a period of 6 months from Feb 2013 to Aug 2013. The data for the study was taken from ADR notification form Case sheets of patients who had an ADR Treatment charts Investigation reports Personal interviews with patient/patient's attendant Personal interviews with reporting persons/clinicians Past history of medication use, which are generally obtained from-Past prescriptions, Reports of Medical and surgical interventions, Referral letters, discharge cards/ Advice on discharge.

The study procedure involved use of some forms for data collection, documentation, causality assessment and analysis of the data. The forms are described below. I. ADR notification of a suspected ADR, II. ADR reporting and documenting form, III. ADR severity assessment scale.

Ethical committee clearance and formal permission from medical superintendent (MS) of Victoria hospital were obtained prior to initiation of the study. Personal meetings with the head of Victoria hospital were held, with a request to report the suspected cases of ADRs. Forms of "Notification of a suspected adverse drug reaction" were made available at the nursing stations and outpatient units. Reported forms were collected and the necessary details are documented. The reports for the notified ADRs were replied to the clinicians/ reporting persons and discussed regarding the causality, management of the particular reaction. Finally the data obtained is analyzed and results are formulated.

The data collection of "Notification of a suspected adverse drug reaction forms" Duly filled ADR reporting forms are collected from the clinicians/reporting persons either during ward rounds or when the outpatient approached clinical pharmacist. 


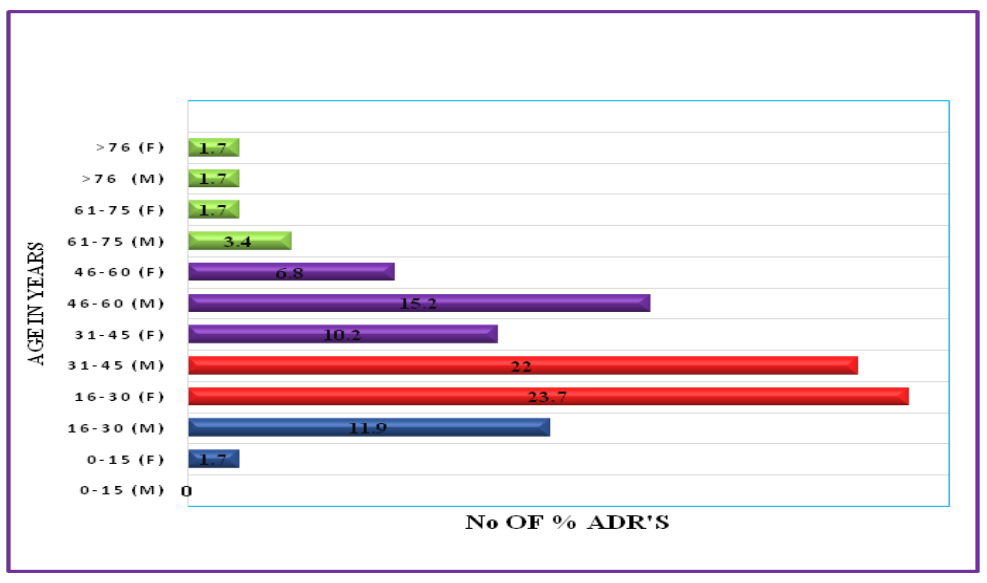

Figure 1: Demographical Data of the Patient Characteristics

This data was documented after receiving the ADR notification forms, only those cases which fulfilled the criteria were included in the study. The details of cases were documented in "Adverse drug reaction reporting and documentation form". Complete history of the patient is taken from case reports, medication charts, and personal interviews with patient and patients' attendants. Disease states of the patients and other comorbid conditions are properly enquired and noted down. Medication history of the patient is obtained from the patient medication slips, prescriptions and also from in-depth patient interview regarding medication use. Sometimes the screening of the remaining medication of the patients that he had used prior to the reaction, which helps in disclosing the facts of medication use and details of the drug products like brand name, manufacturer, Lot no, Exp dates, and other information. Efforts were made to collect as much information as possible.

The causality of the reported ADRs was carried out using "Naranjo causality assessment scale" ${ }^{17}$ assessment of causality based on WHO. ${ }^{19}$ Assessment of severity is based on the Hartwig scale. ${ }^{18}$

The documented cases are followed up daily for documents and to note the prognosis of the patient. patients/patient's attendants are interviewed daily so as to excavate any unnoticed and unseen details of history of the patients and events prior to the reaction. Discussion with reporters/clinicians to give feedback on the reaction and management of the patient condition by providing reports and drug information service.

\section{RESULTS}

A total 77 ADR's from 59 patients were reported during the study period. Among 59 patients, 32 were male and 27 female patients were reported for suspected ADR's.
From total 77 ADR's, $1.7 \%$ for $0-15$ years, $35.6 \%$ for $16-30$ years, $32.2 \%$ for $30-45$ years, $22 \%$ for $46-60$ years, $5.1 \%$ for $61-75$ years and $3.4 \%$ for more than 76 years were observed. During the 6 month of study major ADR's from general medicine (37.2\%), skin department $(28.4 \%)$, others $(29.22 \%)$. (Results were summarized in Figure 1).

Total we observedskin and cutaneous $28.4 \%$, hematology $24.2 \%$, GIT $12.6 \%$, hepatic $13.7 \%$, endocrine system $10.5 \%$, CVS $4.2 \%$, respiratory system $2.1 \%$ and renal $2.1 \%$ were observed during the period 6 month. Similarly, during the study period 59 patients reportedwith maculopapular popularand general rashes $14.8 \%$, abdominal pain $25 \%$, Hemolytic $30.4 \%$ ) and pancytopenia $17.4 \%$, hypotension $75 \%$, hepatotoxicity $53.8 \%$ and hepatitis $23.1 \%$, and hyperglycemia $70 \%$ were observed majorly. In this study we observedantibiotics $20.8 \%$, anti-TB drugs $16.9 \%$, antiviral $14.2 \%$, steroids $10.4 \%$, anticonvulsant $9.1 \%$, NSAID'S $5.2 \%$, diuretics $3.9 \%$, antacids $3.9 \%$, hypoglycemic agents $2.6 \%$, and othersmore than $1 \%$ only were reported and summarized in the Figure 3. Similarly, during the study period 59 patients reportedwith antibiotics cefixime $25 \%$,ceftriaxone $12.5 \%$, in antiviral zidovudine $41.6 \%$ and lamivudine $16.6 \%$. Steroids Dexamethasone and methylprednisolone $37.5 \%$, antituberculosis, Isoniazid and rifampicin $38.46 \%$ and diuretics furesimide $66.6 \%$ major drugs showed the ADR's were reported (Results were summarized in Figure 2). Based on the severity of the reactions only related with the drugs were as follows moderate ADR's 54 (83.0\%), Mild ADR's8 (12.6\%), Sever ADR's3 (4.2\%). 6 ADR's were found drug administration with disease progress moderate ADR's 6 (11.9\%) were observed.

In Total ADRs the Naranjo causality assessment of the reactions only related with the drugs were as follows, possible ADR's 22 (32.35\%), probable ADRs 45 (66.17\%), 


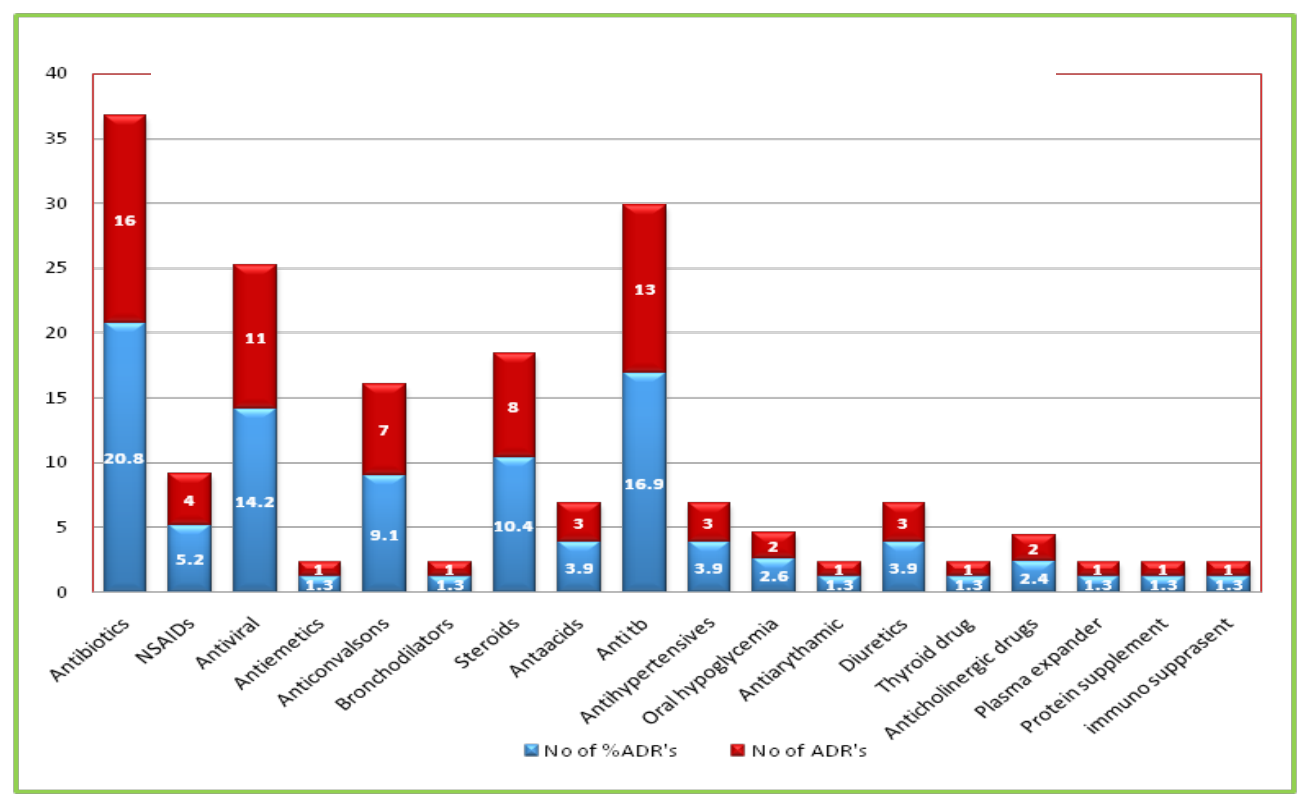

Figure 2: Drug class and Drugs most common Associated ADR's

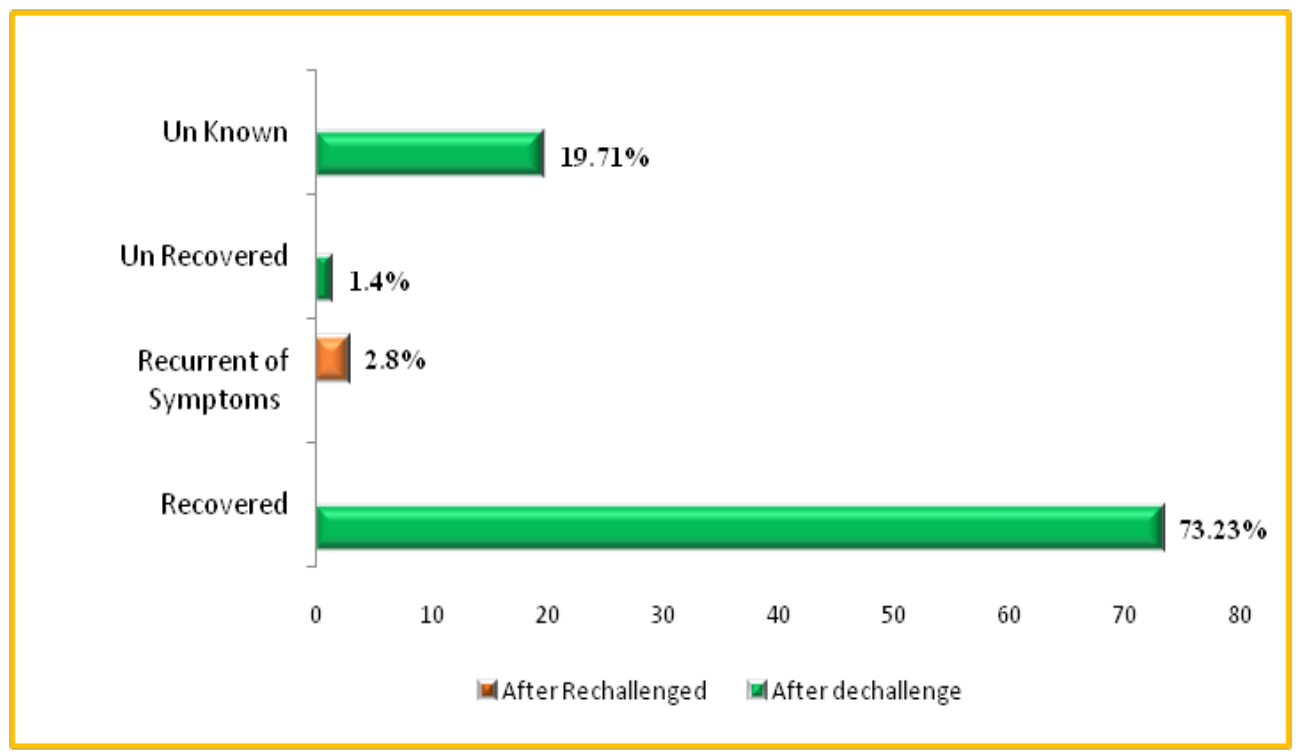

Figure 3: Outcome of ADR's

definite ADRS 1 (1.47\%). Similarly by WHO causality assessment of the reactions as follows. possible ADR's 19 (27.94\%) probable ADR's 32 (47.05\%), certain ADR's 17 (25\%). 6 ADR's were found drug administration with disease progress as per Naranjo and WHO were probable $6(11.9 \%)$ and possible $6(11.9 \%)$. The ADR's associated with disease progress and with drug administration were $11.9 \%$ and antibiotic and antiviral are the main class of drugs which responsible for the ADR's. Based on ADRs classification, $73.91 \%$ ADR's were found to be as Type-A reactions and 26.08\% ADR's were as Type-B reactions.

In the total ADRs during follow up $73.23 \%$ of patients recovered from total ADR's, $1.4 \%$ patient were unrecovered and 19.7\% ADR's in patients were not follow up. Some of patients after rechallenged 2.8\% of symptoms were reappeared in patients (Result were summarized in Figure 3).

\section{DISCUSSION}

ADRs can have a determinant effect on a patient's wellbeing and the overall health care system. ${ }^{20,21} \mathrm{~A}$ comprehensive daily ADR program in a hospital can help to 'complement organizational risk management activities, assess the safety of drug therapies, ADR incidence rates over time and educate health care professionals of drug effects and increase their level of awareness regarding ADRs of new and old drugs. ${ }^{22}$ Overall 59 patients with 
ADRs reported from 180 patients in our study, which included reports from both inpatients and outpatients. In our study, of ADRs in hospitalised patients was, which was low compared to the results of the meta analysis conducted by Mandavi et al., where in 406 from 4005 of hospitalized patients developed an ADR. In our studies outpatients have less number andmore ADRs in inpatients. Two factors might have contributed to this low number in outpatients, the fact that ADRs in these patients are more likely to be mild (patients with reactions of higher level of severity gets admitted in the hospital and hence will be reported as in hospitalized patients) and hence less likely to be reported. Further, ADRs among outpatients are more likely missed to be reported considering the busy schedule of the physicians during outpatient consultations.

There was no significant difference in the incidence of reported ADRs in males and females in our study similar to the results obtained by Montastruc et al. Based on the data collected by ADR reporting. Incidence of ADRs among $0-15$ age is $1.7 \%$, but $16-30$ age group is $32.2 \%$ were significantly higher than other age groups. Very common and common reactions together accounted for almost more percentage of the reports. Reactions to anti-bacterials, antiviral and anti-TB agents accounted for a major share of the reactions in these 77 ADRs. Drug class most commonly involved in the reactions was antibacterial and antiviral agents and hyperglycemic or analgesics were next most commonly reported ADR drugs and these data have similarly reported earlier. ${ }^{23-25}$

Cefixime drug class was one among the commonly implicated classes in few of these studies with hemolytic aniemia. ${ }^{25}$ Phenytoin was the drug most commonly reported for reactions affecting skin and cutaneous and hepatotoxicity accounted for the major share of ADRs, Zidovudine was the drug also commonly associated with the reports in our study with anemia and gastritis.

Dermatological system total ADRs reported (76.6\%) and most commonly affected organ by the ADRs in our study is skin rash $(28.4 \%)$ being the most common individual reaction similar to the results from certain other studies. ${ }^{26}$ Antibacterial was the drug class most commonly implicated in these skin manifestations and hemolytic anemia. Anti-convulasnt such as phyentoin also reported for more of skin manifestation and drug withdrawal or dose reduction is usually the first step to be employed for the management of an ADR in these patients. Antiviral agents were reported for anemia. In our study, $74.6 \%$ of the reports the suspected drug was withdrawn or dose was reduced after the ADR was suspected. No change in therapy and additional treatment was instituted in 9.9\% and $87.3 \%$ of cases. Drug rechallenge was done only in $9.9 \%$ of reports. In majority $(73.23 \%)$ of the reactions patient recovered completely, a finding similar to the one observed by Suh et al. in their study inhospitalized patients. ${ }^{25}$ Most of the reactions belonged to the category probable based on causality assessment similar to the results in another study, but different from the results observed by Murphy and Frigo ${ }^{23}$ in which more of possible reactions were noticed. Only a small percentage of the reactions were severe in nature and mostly skin reactions accounted for the same. Identifying high priority areas in preventable ADRs can greatly contribute to safe and quality drug use. Our analysis revealed a probable rate $65.1 \%$, possible rate is $33.3 \%$ and definite $1.5 \%$. This reveals a great potential for improvising drug therapy in our hospital for safer drug use by addressing these probable events. These studies indicated the prescription of drug provided was safe with preventable events. Studies have shown age, gender, co morbidity, number of drugs, and length of stay in the hospital as significant risk factors for development of ADRs. ${ }^{27-29}$ Our study revealed polypharmacy, multiple disease state and unnecessary use of antibacterial agents as the most prevalent predisposing factors in patients who developed ADRs. Since many of the reports were from medicine department where in usually the patients have multiple co morbidities and hence polypharmacy contributed to the high percentage of reports with these factors as predisposing ones in our study. Age was a contributing factor in many of the reports with 16-45 adult and 45-60 age geriatric groups being the major one. Considering the influence of patient characteristics on the nature of the ADRs, no significant influence of patient characteristics on the system affected by the ADRs and severity of the reactions was observed in our study. In comparison, in the study conducted by Montastruc et al. ${ }^{30}$ An influence of patient characteristics on the severity of the reaction and the organ system affected by the ADRs were observed with serious ADRs more frequently reported in males in the 31-45 age groups (and in females between 16-30 years old).

Under reporting, a well known $\backslash$ limitation of spontaneous reporting program needs to be taken into consideration while interpreting the data. Since the study data was obtained from only one hospital, the results may not be generalisable to the entire population. But, our study data would give an insight into to the pattern of ADRs which do occur in tertiary care hospitals with a comparable pattern of patient demographics and drug usage.

In some of the reports, the outcome of the ADR after dechallenge and rechallenge could not be assessed due to lack of patient follow up. The outcome data if available could have probably altered the causality assessment 
results in these reports. Further, in certain of the reports involving dermatological system, skin manifestations were mentioned in general as skin rash without any specific description and hence proper categorization of skin manifestations could not be done is these reports. This probably could have affected the categorization of the reactions as moderate or mild during severity assessment. During preventability analysis, while considering the parameter 'whether the drug and the regimen used was appropriate for the patient', the judgment of the study investigators was taken into consideration which could have been probably different in some of the reports from the treating clinicians justification for the use of the drug. The classification of ADR's studies most of reported in the published article as Type A and Type B. ${ }^{31}$ In present studies we got type-A reactions as $26.08 \%$ and type- $\mathrm{B}$ as $73.92 \%$. Most of ADR's are unprectibile and not a dose dependent (Type B) found in our studies. These reactions normally not dose dependent and not expected from the known pharmacological reactions. We considered reducing this potential source of error by following the recommendations by European commission's guidelines. ${ }^{32}$

In conclusion, the pattern of ADRs reported in our hospital is comparable with the results from studies conducted elsewhere in hospital set up. Results of many of the evaluated parameters were similar to other studies ${ }^{25-}$ ${ }^{27}$ while some aspects were different from other studies. ${ }^{33,34}$ Difference in drug usage pattern in our set up from the settings in which the other studies were conducted could have contributed to the difference in pattern. Systematic tracking and monitoring of ADR scan shed light on their extensiveness and patterns of occurrence.

\section{CONCLUSION}

Such studies enables in obtaining information on the incidence and pattern of ADRs in the local population. The present evaluation has revealed opportunities for interventions especially for the avoidable ADRs which will help in promoting safer drug use in institutions. Similar data evaluation needs to be followed by dissemination of the information to the healthcare professionals, which helps to improve the quality of patient care by ensuring safer use of drugs. Similar reporting programs are necessary to educate and to increase awareness about reporting of ADRs among the healthcare professionals in the all the hospital in India.

\section{ACKNOWLEDGEMENTS}

Special Thanks to our project guide Dr. V.M. Chandrashekhar M.Pharm, Ph.D. HOD of Department of Clinical Pharmacy, Co-guide Mr. Arun. R M. Pharm. We also express humble thanks to Dr. I.S Muchchandi M.Pharm. Ph.D, Principal and HOD in H.S.K College of Pharmacy; Dr. Ashok Mallapur, Principal in S.N. Medical College; Dr. Chandrashekar T.M Dean S.N Medical College \& H.S.K Hospital \& Research center, Navanagar, Bagalkot.

My Heart full thanks to ideal person Mr. K. Seshagirirao.

\section{CONFLICT OF INTEREST}

We were indicated to the health care professionals andproviding awareness to the patient about severity ofADRs. We were provided support and knowledge about prevention of ADRs to the health care professionals and also given drug usage knowledge to the patient.

\section{ABBREVIATIONS USED}

$\begin{array}{lr}\text { ADR : } & \text { Adverse Drug Reaction } \\ \text { VD : } & \text { Venereology Department } \\ \text { CDSCO: } & \text { Central Drug Standard Control Orga- } \\ \text { ni } & \text { zation } \\ \text { WHO : } & \text { World Health Organization } \\ \text { FDA : } & \text { Food and Drug Administra- } \\ \text { tion } & \\ \text { ASHP : } & \text { Australian Society of Health-System } \\ \text { NSAID : } & \text { Non-Steroidal Anti Inflammatory } \\ \text { Drugs } & \text { Angiotenage Converting En- } \\ \text { ACE : } & \end{array}$

\section{REFERENCES}

1. Ditto AM. Drug allergy. In: Grammer LC, Greenberger PA, editors. Patterson's allergic diseases. $6^{\text {th }}$ ed. Philadelphia: Lippincott Williams and Wilkins; 2002. p. 295.

2. Jick H. Adverse drug reactions: the magnitude of the problem. J Allergy Clin Immunol. 1984;74(4):555-7.

3. Lazarou J, Pomeranz BH, Corey PN. Incidence of adverse drug reactions in hospitalized patients: a meta-analysis of prospective studies. Journal American Medical Association. 1998;279(15):1200-5.

4. Hartwig SC, Siegel J, Schneider PJ. Preventability and severity assessment in reporting adverse drug reactions. Am J Hosp Pharm. 1992;49(9):2229-32.

5. American Society of Health System Pharmacists. ASHP guidelines on adverse drug reaction monitoring and reporting. Am J Hosp Pharm. 1989;46(16):336-7.

6. Murphy BM, Frigo LC. Development, implementation, and results of a successful multidisciplinary adverse drug reaction reporting program in a university teaching hospital. Hosp Pharm. 1993;28(12):1199-204, 1240.

7. Moride $Y$, Haramburu F, Requeyo AA, Begaud B. Underreporting of adverse drug reactions in general practice. Br J Clin Pharmacol. 1997;43(2):177-81.

8. Alvarez-Requejo A, Carvajal A, Begaud B, Moride Y, Vega T, Martin Arias $\mathrm{LH}$. Under reporting of adverse drug reactions. Estimate based on a spontaneous reporting scheme and a sentinel system. Eur J Clin Pharmacol. 1998;54(6):483-8.

9. Gallelli L, Ferreri G, Colosimo M, Pirritano D, Flocco MA, Pelaia G. Retrospective analysis of adverse drug reactions to bronchodilators observed 
in two pulmonary divisions of Catanzaro, Italy. Pharmacol Res. 2003;47(6):4939.

10. Wu WK. Evaluation of outpatient adverse drug reactions leading to hospitalization. Am J Health-Syst Pharm. 2003;60(3):253-9.

11. Regal B. Finally a pharmacovigilant India. Uppsala Rep. 2004;25(06):7-8.

12. Adithan C. National pharmacovigilance program. Indian J Pharmacol. 2005;37(6):347.

13. Requirements for adverse reaction reporting. Geneva, Switzerland: World Health Organization; 1975.

14. Karch FE, Lasagna L. Adverse drug reactions-a critical review. Journal American Medical Association. 1975;234(12):1236-41.

15. Kessler DA. Introducing MedWatch, using FDA form 3500, a new approach to reporting medication and device adverse effects and product problems. Journal American Medical Association. 1993;269(12):2765-8.

16. Bhatt $A D$. Drug related problems and adverse drug events: Negligence, litigation and prevention. Journal of the Association of Physicians of India. 1999;47(7):715-20.

17. Naranjo CA, Busto U, Sellers EM, Sandor P, Ruiz I, Roberts EA. A method for estimating the probability of adverse drug reactions. Clin Pharmacol Ther. 1981;30(27):239-45.

18. Hartwig SC, Siegel J, Schneider PJ. Preventability and severity assessment in reporting adverse drug reactions. Am J Hosp Pharm. 1992;49(9):2229-32.

19. Meyboom RHB. Causal or Casual? The Role of Causality Assessment in Pharmacovigilance. Drug Safety.1997;17(6):374-89.

20. Lazarou J, Pomeranz BH, Corey PN. Incidence of adverse drug reactions in hospitalized patients: a meta-analysis of prospective studies. JAMA. 1998;279(15):1200-5.

21. Bates DW, Spell N, Cullen DJ, Burdick E, Laird N, Petersen LA. The cost of adverse drug events in hospitalized patients. JAMA. 1997;277(4):307-11.

22. American Society of Health System Pharmacists. ASHP guidelines on adverse drug reaction monitoring and reporting. Am J Hosp Pharm. 1989;46(16):336-7.
23. Murphy BM, Frigo LC. Development, implementation, and results of a successful multidisciplinary adverse drug reaction reporting program in a university teaching hospital. Hosp Pharm. 1993;28(12):1199-204, 1240.

24. Bates DW, Cullen DJ, Laird N, Petersen LA, Small SD, Servi D. Incidence of adverse drug events and potential adverse drug events-implications for prevention. JAMA. 1995;274(1):29-34.

25. Suh DC, Woodall BS, Shin SK, Hermes-De-Santis ER. Clinical and economic impact of adverse drug reactions in hospitalized patients. Ann Pharmacotherapy. 2000;34(12):1373-9.

26. Kanjanarat P, Winterstein AG, Johns TE, Hatton RC, Gonzalez-Rothi R, Segal R. Nature of preventable adverse drug events in hospitals: a literature review. Am J Health Syst Pharm. 2003;60(17):1750-9.

27. Gonzalez-Martin G, Caroca CM, Paris E. Adverse drug reactions (ADRs) in hospitalized pediatric patients-a prospective study. Int $\mathrm{J}$ ClinPharmacolTher. 1998;36(10):530-3.

28. Bates DW, Leape LL, Petrycki S. Incidence and preventability of adverse drug events in hospitalized adults. J Gen Intern Med. 1993;8(6):289-94.

29. Gandhi TK, Weingart SN, Borus J, Seger AC, Peterson J, Burdick E. Adverse drug events in ambulatory care. N Eng J Med. 2003;348(16):1156-64.

30. Montastruc JL, Lapeyre-Mestre M, Bagheri H, Fooladi A. Gender differences in adverse drug reactions: analysis of spontaneous reports to a Regional Pharmacovigilance Centre in France. Fundam Clin Pharmacol. 2002;16(5):343-6.

31. Roger walker'stextbook of clinical pharmacy, $3^{\text {rd }}$ edt. Roger walker,clive Edwards, Churchill livingstone publication: 2003, Page no 33-46.

32. European Commission. A guideline on summary of product characteristics, October 2005.http://pharmacos.eudra.org/F2/eudralex/vol-2/C/SPCGuidRev0Dec 99.pdf.

33. Gholami K, Shalviri G. Factors associated with preventability, predictability, and severity of adverse drug reactions. Ann Pharmacother. 1999;33(2):236-40.

34. Prosser TR, Kamysz PL. Multidisciplinary adverse drug reaction surveillance program. Am J Hosp Pharm. 1990;47(6):1334-9. 